ఠ

Open Access Full Text Article

ORIGINAL RESEARCH

\title{
Antidiabetic effect of glucosaminic acid-cobalt (II) chelate in streptozotocin-induced diabetes in mice
}

\section{Tahirou Talba' \\ Xia Wen Shui' \\ Qinyuan Cheng ${ }^{1,2}$ \\ Xin $\operatorname{Tian}^{2}$}

'Key Laboratory of Food Processing Technology, ${ }^{2}$ School of Medicine and Pharmaceutics, Jiangnan University, Wuxi, Jiangsu, People's Republic of China
Correspondence: Xia Wen Shui School of Medicine and Pharmaceutics, Jiangnan University, Wuxi, Jiangsu 2/4I22, People's Republic of China

Tel +8651085913299

Fax +86 510 859। 3299

Email talbat@yahoo.fr
This article was published in the following Dove Press journal:

Diabetes, Metabolic Syndrome and Obesity:Targets and Therapy 22 April 2011

Number of times this article has been viewed

Background: The purpose of this study was to assess the in vivo ability of glucosaminic acid-cobalt (II) chelate to reduce glycemia.

Methods: Different concentrations of chelate solution were administrated to mice with diabetes induced by streptozotocin.

Results: Daily oral administration of chelate solution $0.4 \mathrm{~mL}$ at various concentrations $(0.32-$ $0.4 \mathrm{~g} / \mathrm{mL}$ ) led to reduction in water intake by the diabetic mice after 5 days of treatment, with a subsequent reduction in glucose levels observed 2 weeks later. Daily food intake was related to both chelate concentration as well as glycemia reduction. The food intake of mice treated with glucosaminic acid-cobalt (II) chelate solution was 1.5-fold that of untreated mice.

Conclusion: Glucosaminic acid-cobalt chelate was effective as an antidiabetes agent; its efficacy was proportional to treatment period. The chelated form expressed much less toxicity compared to cobalt only, and stimulated subsequent food intake after daily administration.

Keywords: glucosaminic acid, cobalt, chelate, streptozotocin, glycemia reduction

\section{Introduction}

Diabetes mellitus, often simply referred to as diabetes, is a group of metabolic diseases in which a person has high blood sugar, either because the body does not produce enough insulin, or because cells do not respond to the insulin that is produced. This high blood sugar produces the classical symptoms of polyuria, polydipsia, and polyphagia. ${ }^{1}$ The chronically higher level of blood sugar generates damage in various organs, especially the eyes, kidneys, nerves, and heart, as well as the blood vessels.

The number of people with diabetes is expected to increase dramatically in the coming decades, rising to 380 million people by 2025. Developed countries have higher prevalence rates than developing countries, but the latter will be hit hardest by the diabetes epidemic. Increased urbanization, westernization, and economic development in developing countries have already contributed to a substantial rise in diabetes. ${ }^{2,3}$ The development of diabetes complications contributes substantially to the elevated death rates in diabetic patients. The mechanism by which diabetes leads to these complications is complex and not yet fully understood, but involves the direct toxic effects of high glucose levels, along with the impact of elevated blood pressure, abnormal lipid levels, and oxidative stress, as well as being a chronic inflammatory condition. ${ }^{4}$

Type 1 (insulin-dependent) diabetes mellitus is characterized by loss of the insulin-producing beta cells of the islets of Langerhans in the pancreas, leading to insulin deficiency. This type of diabetes can be further classified as immune-mediated or idiopathic. 
The majority of type 1 diabetes is of an immune-mediated nature, whereby beta cell loss is a T cell-mediated autoimmune attack. ${ }^{5,6}$ Cobalt has been demonstrated to boost the effects of insulin and its action. ${ }^{6}$ The efficiency of cobalt as an antidiabetic agent has been proven. However, the use of cobalt in its single and pure form may be lethal to patients. ${ }^{6,7}$ Therefore, it is crucial to implement research to identify new agents that can reduce the potential toxicity of cobalt without impacting on its efficacy.

In the present work we evaluated the ability of glucosaminic acid-cobalt (II) chelate to lower glycemia levels in mice with streptozotocin-induced diabetes.

\section{Materials and methods}

\section{Animals}

Thirty male mice with a body weight of $16-18 \mathrm{~g}$ were purchased from the Shanghai Laboratory Animal Center (Shanghai, China). The mice were housed five per cage at room temperature regulated to $22-24^{\circ} \mathrm{C}$ in the experimental animal facility of the School of Medicine and Pharmaceutics, Jiangnan University. They were fed for 1 week to standardize body weight at the minimum value of $20 \mathrm{~g}$. Diabetes was induced by injection of freshly prepared concentrated streptozotocin $(7.5 \mathrm{mg} / \mathrm{mL})$ in sodium citrate buffer. Each mouse was injected with $0.2 \mathrm{~mL}$ in the tail vein for 5 consecutive days. One week after injection, blood samples were taken from the caudal vein after the mice were anesthetized. Fasting blood glucose and total body weights were recorded, and the mice were divided into three groups. The experimental protocol conformed with the ethics regulations and procedures instituted by the School of Medicine and Pharmaceutics at Jiangnan University.

\section{Experimental design}

The diabetic mice were divided into three groups ( $\mathrm{n}=10$ per group), ie, Group A (fed as for Groups B and C except that instead of the chelate solution they were given $0.4 \mathrm{~mL} /$ day of double-distilled water), Group B (given $0.4 \mathrm{~mL} /$ day of $0.32 \mathrm{~g} / \mathrm{mL}$ chelate solution), and Group C (given $0.4 \mathrm{~mL} /$ day of $0.4 \mathrm{~g} / \mathrm{mL}$ chelate solution). The food and water intake of all three groups was recorded daily. Body weight and blood glucose levels were determined every week. The experiment was carried out for 5 weeks after streptozotocin administration. At the end of the experiment and after 12 hours of fasting, all animals were sacrificed. Blood samples were collected from the heart, placed on ice, and centrifuged within 10 minutes of sample collection. Serum was stored at $-20^{\circ} \mathrm{C}$ for 7 days before analysis.

\section{Statistical analysis}

Results were expressed as the mean of triplicate experiments. One-way analysis of variance with a Student's Newman-Keuls post hoc comparison was used to test for statistical significance, set at $P<0.05$.

\section{Results and discussion Effect of chelate on body weight and daily water/food intake}

The body weight of the diabetic mice during treatment increased to a maximum individual value of $27 \mathrm{~g}$ by the end of the third week of the experiment (Figure 1). However, this value did not decrease at the final week. The stability in body weight was in contrast with previous work, ${ }^{7}$ and might be attributed to the fact that chelating cobalt to glucosaminic acid reduced its toxicity and potential side effects, including diarrhea, which is mostly responsible for the decrease in body weight. No significant $(P<0.05)$ differences in body weight were seen in the treated mice. However, their values were significantly $(P<0.05)$ higher than that of the control mice by the fifth week of the experiment. This relative difference might be related to the decrease in food intake as a result of the increase in blood sugar over the treatment period.

Tables 1 and 2 show the analytical data for water and food intake, respectively, in the different groups of mice used in this study.

The volume of water intake in Group A was higher and continued to increase up to the end of the experiment, and was estimated to be three-fold that of Group C. In Group B (receiving $0.4 \mathrm{~mL} /$ day of chelate $0.32 \mathrm{~g} / \mathrm{mL}$ solution), a decrease in daily water intake was observed after the first week of treatment, while in Group C (receiving $0.4 \mathrm{~mL} /$ day of chelate $0.4 \mathrm{~g} / \mathrm{mL}$ solution), a decrease in daily water intake was

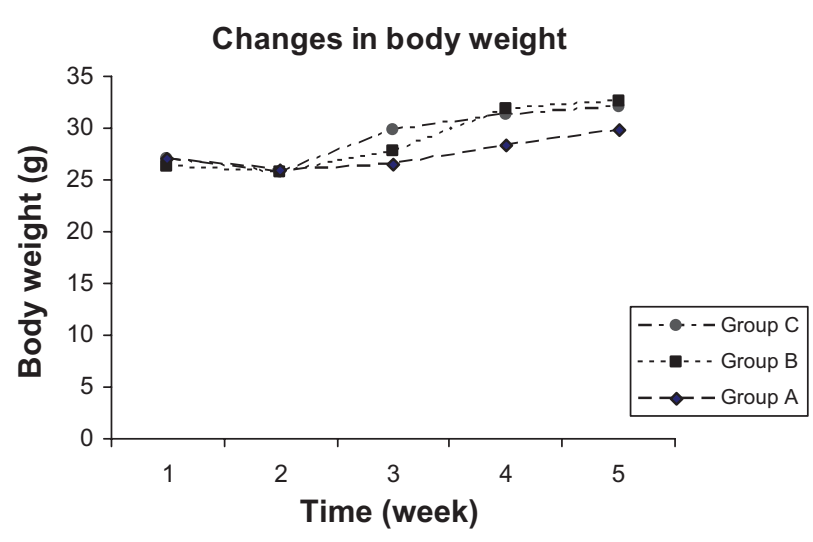

Figure I Changes in body weight in mice with streptozotocin-induced diabetes. 
Table I Water intake in rats with streptozotocin-induced diabetes

\begin{tabular}{llllllll}
\hline \multicolumn{1}{l}{ Water intake $(\mathbf{m L})$} & & & \\
\cline { 2 - 7 } & 5th day & I0th day & I5th day & 20th day & 25th day & 30th day & 35th day \\
\hline Group A & 128.12 & 130.43 & 140.76 & 143.23 & 152.91 & 161.27 & 156.97 \\
Group B & 130.02 & 108.31 & 97.37 & 95.08 & 86.11 & 63.33 & 54.61 \\
Group C & 112.21 & 98.11 & 76.66 & 63.53 & 52.71 & 44.55 & 43.68 \\
\hline
\end{tabular}

observed after 5 days of treatment, but the value was still higher compared with water intake prior to induction of diabetes.

Major differences were observed in terms of food intake. Treated mice had an over 1.5-fold higher food intake compared with diabetic mice throughout the experiment. This was in opposition to the results reported by Yagmaei et $\mathrm{al}^{8}$ indicating a decrease in food intake for treated animals. The relative increase in food intake was observed from the sixth day of treatment, and this generated a difference in body weight between treated and untreated mice. The relative increase in food intake might be due to the fact that administration of a higher dose of glucosaminic acid-cobalt chelate enhanced relaxation in diabetic mice. It has been shown that cobalt or its chelated form might attenuate the vasoconstrictor response. ${ }^{9}$

\section{Glycemia-lowering effect of chelate}

The glycemia-lowering effect of chelate on mice with streptozotocin-induced diabetes was determined weekly for a period of 5 weeks. At indicated times, blood samples were taken for glycemia level determination using (ACCU-CHEK Active, Roche Diagnostics GmbH, Mannheim, Germany). Figure 2 describes the glycemia-lowering effect of the chelate for the three groups of mice in this experiment. As expected, the glycemia level for treated mice was higher and kept increasing until the end of the experiment. The glycemia concentration exceeded $34 \mathrm{mmol} / \mathrm{L}$ in two mice. At the end of the first week of treatment, no significant decrease was observed for glycemia in treated mice. However, in contrast with Group A mice, glycemia values were relatively stable in the groups of diabetic treated mice.

The effect of administration of chelate at a higher concentration $(1.5 \mathrm{~g} / \mathrm{mL})$ was dramatic in diabetic mice and we reached this finality in a pre-experiment study. Ybarra et $\mathrm{al}^{7}$ concluded that the toxicity of cobalt at a higher dose led to death. In the case of the chelated form, the lethal toxicity at the higher dose might be due to the fact that additional intake was conjugated to the previous unused dose. Mice present with a smaller digestion system compared with rats or other larger animals, and thus take longer to deplete their previous intake.

When the higher dose was administered, the mice did not exhaust the previous dose, and therefore, when a new dose was administered and conjugated with the rest of the previous dose, and thereby increasing the total daily dose, death ensued. In comparison with previous work on use of cobalt only, we conclude that efficiency of the chelate in diabetic animals was significant at certain doses almost 1 week after treatment, while the single administration of cobalt chloride ${ }^{7}$ generated efficient results after just 3 days of treatment. This finding is in agreement with numerous works on the glycemia-lowering effect of metal ions, ${ }^{9-11}$ but the mechanism is still obscure. At the end of 5 weeks of treatment, all the mice were still diabetic but the blood sugar for treated mice had decreased dramatically. In case of Group C (receiving the daily higher dose), the glycemia level determined at the fifth week $(12.89 \mathrm{mmol} / \mathrm{L})$ was closer to the value in a nondiabetic animal without fasting. For Groups B and $\mathrm{C}$, no significant difference in blood sugar was observed from the fourth week of study onwards $(P<0.05)$.

\section{Conclusion}

The use of glucosaminic acid-cobalt chelate as a glycemialowering drug was effective. Its efficacy was proportional to the treatment duration. The daily intake of this chelate was nontoxic at a reasonable dose and stimulated subsequent food intake. The use of cobalt only ${ }^{3}$ in antidiabetic treatment appears to be less time-consuming, but has higher toxicity compared with the chelated form.

Table 2 Food intake in mice with streptozotocin-induced diabetes

\begin{tabular}{llllllll}
\hline & \multicolumn{7}{l}{ Food intake $(\mathbf{g})$} \\
\cline { 2 - 7 } & 5th day & I0th day & 15th day & 20th day & 25th day & 30th day & 35th day \\
\hline Group A & 106.08 & 87.05 & 83.40 & 79.15 & 63.38 & 60.63 & 61.81 \\
Group B & 103.12 & 112.32 & 127.32 & 108.34 & 101.26 & 103.43 & 113.37 \\
Group C & 101.02 & 109.21 & 129.01 & 121.01 & 109.63 & 111.31 & 112.48 \\
\hline
\end{tabular}




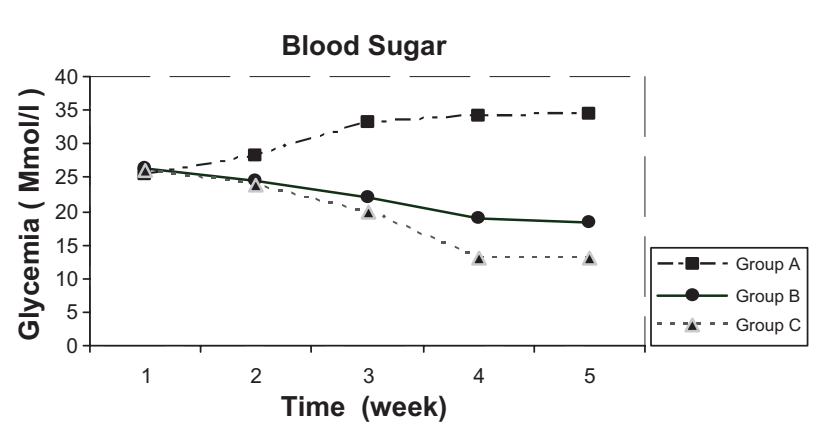

Figure 2 Blood sugar in mice with streptozotocin-induced diabetes.

\section{Acknowledgments}

The authors thank the Exploring Program of State Key Laboratory of Food Science and Technology, Jiangnan University, and the Nature Science Foundation of Jiangsu Province for their financial support.

\section{Disclosure}

The authors report no conflicts of interest in this work.

\section{References}

1. Diabetes mellitus. Available at: http://en.wikipedia.org/wiki/Diabetes_ mellitus. Accessed February 18, 2011.

2. Global Diabetes Information and Statistics. Available at: http:// medicalcenter.osu.edu/pdfs/healthcare_professionals/information statistics.pdf. Accessed February 18, 2011.
3. Wild S, Roglic G, Green A, et al. Global prevalence of diabetes: Estimates for the year 2000 and projections for 2030. Diabetes Care. 2004;27:1047-1053.

4. Pu LI, Lu L, Xu XW, et al. Value of serum glycated albumin and high-sensitivity C-reactive protein levels in the prediction of presence of coronary artery disease in patients with type 2 diabetes. Cardiovasc Diabetol. 2006;5:27.

5. Rother KI. Diabetes treatment - bridging the divide. $N$ Engl $J$ Med. 2007;356:1499-1501.

6. Vasudevan H, McNeill JH. Chronic cobalt treatment decreases hyperglycemia in streptozotocin-diabetic rats. Biometals. 2007;20: 129-134.

7. Ybarra J, Behrooz A, Gabriel A, Koseoglu MH, Ismail-Beigi. Glycemia-lowering effect of cobalt chloride in the diabetic rat: Increased GLUT1 mRNA expression. Mol Cell Endocrinol. 1997;133:151-160.

8. Yaghmaei P, Parivar K, Niksereshet F, Amini S, Masoudi A, Amini E. Pancreatic protective effects of sodium tungstate in streptozotocininduced diabetic rats. Diabetes and metabolic syndrome: Clinical Research and Reviews. 2008;2:259-265.

9. Di Pascoli M, Rodella L, Sacerdoti D, Bolognesi M, Turkseven S, Abraham NG. Chronic CO levels have a beneficial effect on vascular relaxation diabetes. Biochem Biophys Res Commun. 2006;340: 935-943.

10. Frank A, Sell DR, Danielsson R, Fogarty JF, Monnier VM. A syndrome of molybdenosis, copper deficiency, and type 2 diabetes in the moose population of south-west Sweden. Sci Total Environ. 2000;249: 123-131.

11. Barberà A, Rodríguez-Gil JE, Guinovart JJ. Insulin-like actions of tungstate in diabetic rats: Normalization of hepatic glucose metabolism. J Biol Chem. 1994;269:20047-20053.

\section{Publish your work in this journal}

Diabetes, Metabolic Syndrome and Obesity: Targets and Therapy is an international, peer-reviewed open-access journal committed to the rapid publication of the latest laboratory and clinical findings in the fields of diabetes, metabolic syndrome and obesity research. Original research, review, case reports, hypothesis formation, expert opinion and commentaries are all considered for publication. The manuscript management system is completely online and includes a very quick and fair peer-review system, which is all easy to use. Visit $\mathrm{http}: / /$ www.dovepress.com/testimonials.php to read real quotes from published authors. 